\title{
A New Evaluation of Skin Factor in Inclined Wells with Anisotropic Permeability
}

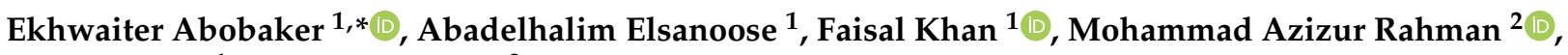 \\ Amer Aborig ${ }^{1}$ and Khalid Noah ${ }^{3}$ \\ 1 Faculty of Engineering and Applied Science, Memorial University of Newfoundland, \\ St. John's, NL A1C 5S7, Canada; amge58@mun.ca (A.E.); fikhan@mun.ca (F.K.); amaborig@mun.ca (A.A.) \\ 2 Petroleum Engineering, Texas A\&M University at Qatar, Doha 23874, Qatar; marahman@tamu.edu \\ 3 Faculty of Engineering, University of Tobruk, Tobruk, Libya; knoah@tu.edu.ly \\ * Correspondence: eera48@mun.ca
}

Citation: Abobaker, E.; Elsanoose, A.; Khan, F.; Rahman, M.A.; Aborig, A.; Noah, K. A New Evaluation of Skin Factor in Inclined Wells with Anisotropic Permeability. Energies 2021, 14, 5585. https://doi.org/ 10.3390/en14175585

Academic Editor: Guglielmo Lomonaco

Received: 2 August 2021

Accepted: 31 August 2021

Published: 6 September 2021

Publisher's Note: MDPI stays neutral with regard to jurisdictional claims in published maps and institutional affiliations.

Copyright: (c) 2021 by the authors. Licensee MDPI, Basel, Switzerland. This article is an open access article distributed under the terms and conditions of the Creative Commons Attribution (CC BY) license (https:/ / creativecommons.org/licenses/by/ $4.0 /)$.

\begin{abstract}
Oil and gas well productivity can be affected by a number of different skin factors, the combined influences of which contribute to a well's total skin factor. The skin caused by deviated wells is one such well-known factor. The present study aimed to investigate skin effects caused by deviated well slants when considering vertical-to-horizontal permeability anisotropy. The research employed computational fluid dynamics (CFD) software to simulate fluid flows in inclined wells through the injection of water with Darcy flow using 3D geometric formations. The present work investigates the effects of four main characteristics—namely, the permeability anisotropy, wellbore radius, reservoir thickness, and deviation angle-of open-hole inclined wells. Additional investigations sought to verify the effect of the direction of perforations on the skin factor or pressure drop in perforated inclined wells. In the case of an inclined open hole well, the novel correlation produced in the current study simplifies the estimation of the skin factor of inclined wells at different inclination angles. Our comparison indicates good agreement between the proposed correlation and available models. Furthermore, the results demonstrated a deviation in the skin factor estimation results for perforated inclined wells in different perforation orientation scenarios; therefore, existing models must be improved in light of this variance. This work contributes to the understanding and simulation of the effects of well inclination on skin factor in the near-wellbore region.
\end{abstract}

Keywords: skin factor; inclined wells; anisotropic permeability; CFD

\section{Introduction}

To a great extent, a well's geometry may determine its production performance. Common geometrical shapes of wells include inclined, undulating, multi-branched, horizontal, and vertical. Both the increasing complexity of sites as a result of drilling in non-traditional locations and the geological condition of the reservoir increase the overall complexity. To overcome these potential challenges, technology developed for inclined wells is beginning to be used during the extraction stage. The extent to which inclination affects an inclined open-hole well may be quantified using the inclination pseudo-skin factor. Investigations of transient inclined well solutions show radial flows around the length of the inclined well, which can be applied when determining the effects of combined well deviation and formation damage. In the damaged zones, flow convergence caused by well deviation typically occurs close to the near-wellbore region prior to the entry of the fluid into the damaged zone. Figure 1 presents a schematic of flow convergence at a formation-damaged deviated well.

In the case of completely or partially perforated wells where the flow is located far from a wellbore, fluid typically moves along a radial-like flow in the general direction of the wellbore. This flow type usually occurs in cases of wells designated as partially perforated vertical structures. In such cases, well inclination and perforations have little impact on 
fluid streamlines. Instead, as the fluid nears the wellbore, the streamlines slowly converge until they are perpendicular in relation to the axis of the wellbore. This results in a pseudoradial flow that surrounds the inclined wellbore prior to arrival at the perforated well. When the fluid streamlines finally do reach the near-wellbore region, they are redirected due to perforations and formation damage, as shown in Figure 2.

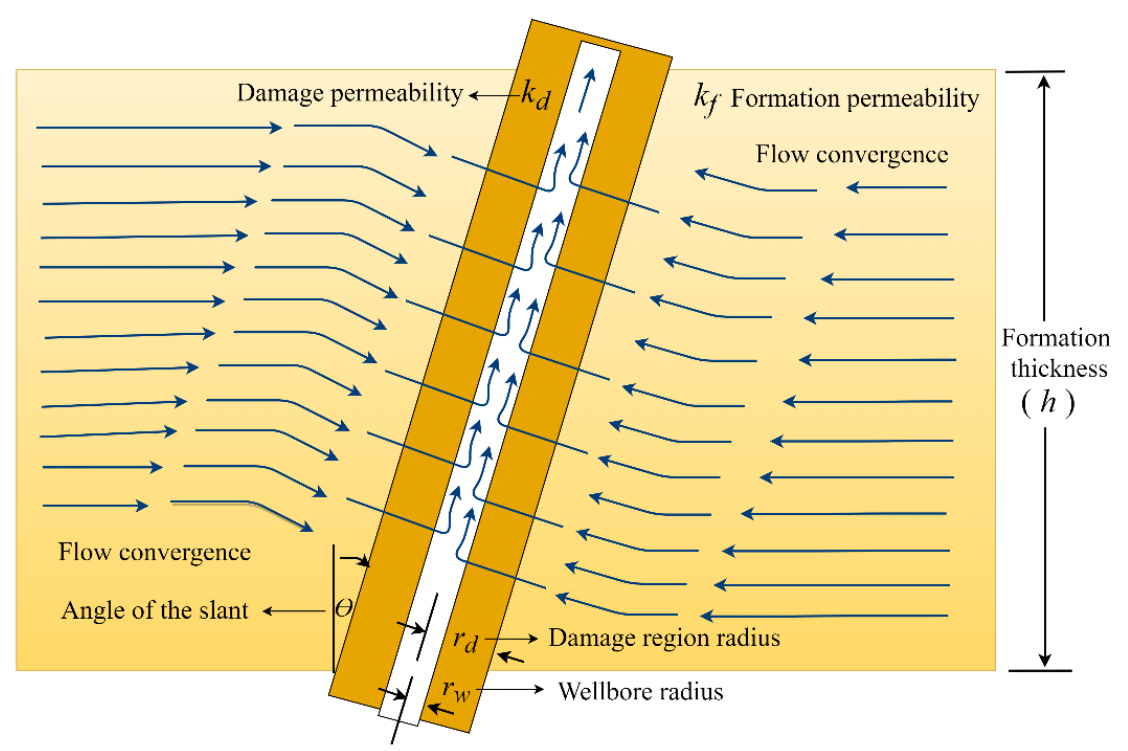

Figure 1. Schematic of inclined open-hole well flow with formation damage.

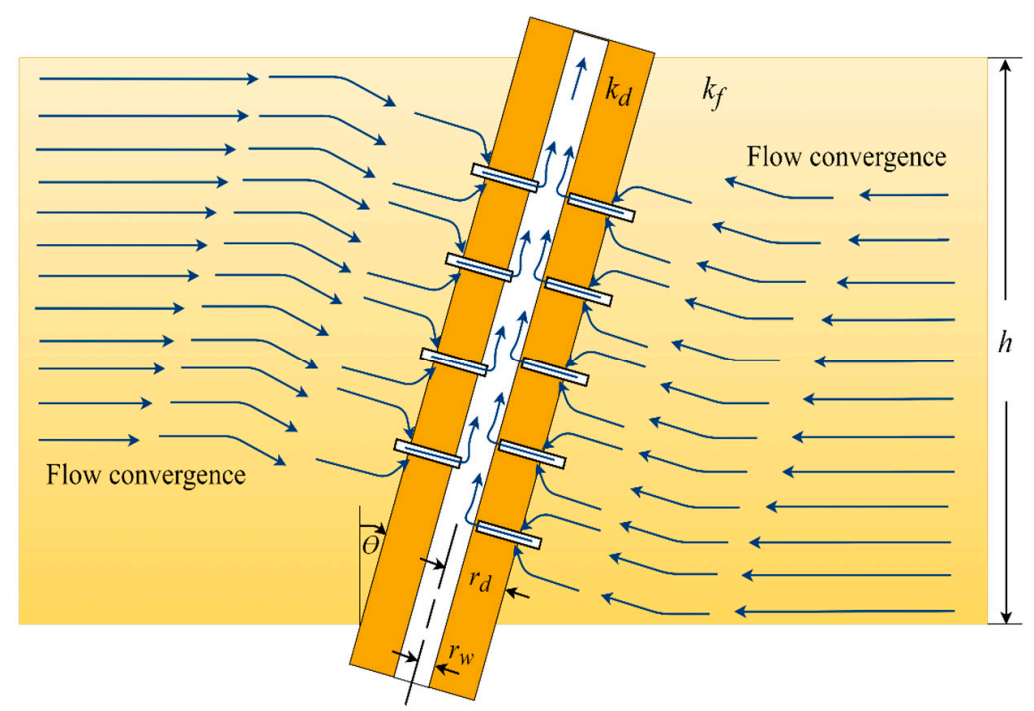

Figure 2. Schematic of inclined and completely perforated well with perforations. Perpendicular to well and formation damage.

In inclined wells, the pressure transient behavior needs to be determined with mathematical models. Many models have been developed over the past several decades for the prediction of perforated skin for inclined wells; Cinco, Miller, and Ramey (1975) [1] described analytical solutions for inclined wells that take into account pseudo-radial flow periods for relatively large time values. The slant pseudo-skin equation of Cinco et al. (1975) is commonly applied when estimating how a well's productivity is influenced by incli- 
nation. After determining the pseudo-skin's inclination, the additional pressure change caused by well deviation can be expressed as follows:

$$
\begin{gathered}
S_{\theta}\left(\dot{\theta}, h_{D}\right)=-\left(\frac{\dot{\theta}}{41}\right)^{2.06}-\left(\frac{\dot{\theta}}{56}\right)^{1.865} \times \log \left(\frac{h_{D}}{100}\right) \\
h_{D}=\frac{h}{r_{w}} \sqrt{\frac{k_{h}}{k_{v}}} \\
\text { For } 0^{\circ} \leq \theta \leq 75^{\circ}, \dot{\theta}=\tan ^{-1}\left(\sqrt{\frac{k_{v}}{k_{h}}} \times \tan (\theta)\right)
\end{gathered}
$$

Later, (Besson 1990) employed a semi-analytical simulator to determine pressure decline curves in slant horizontal wells located within an isotropic, infinite, and homogeneous formation.

$$
S_{\theta}=\ln \left(\frac{4 r_{w}}{L}\right)+\frac{h}{L} \ln \left(\frac{\sqrt{L h}}{4 r_{w}}\right)
$$

This formula can then be changed to accommodate an anisotropic reservoir via spatial transformation (i.e., real medium to isotropic medium) (Besson 1990) [2], as shown in Equation (5) below:

$$
\begin{gathered}
S_{\theta}=\ln \left(\frac{4 r_{w}}{L} \frac{1}{I_{a n i} \gamma}\right)+\frac{h}{\gamma L} \ln \left(\frac{\sqrt{L h}}{4 r_{w}} \frac{2 I_{a n i} \sqrt{\gamma}}{1+\frac{1}{\gamma}}\right) \\
\gamma=\sqrt{\cos ^{2} \theta+\frac{1}{I_{a n i}{ }^{2}} \sin ^{2} \theta} \\
I_{a n i}=\sqrt{\frac{k_{h}}{k_{v}}}
\end{gathered}
$$

Rogers and Economides (1996) [3] later developed a correlation that involved the skin's complete penetration of deviated wells located in anisotropic reservoirs. The researchers employed a semi-analytical productivity index model proposed previously by Besson (1990) [2]. The model was intended to be applied in horizontal wells as a means of taking well deviation into account. To measure the effect of anisotropy, Rogers and Economides (1996) [3] applied the transformation used in the experiments of Besson (1990) [2].

$$
\begin{aligned}
& \text { For } I_{a n i}<1, S_{\theta}=-1.64 \frac{\sin \theta^{1.77} h_{d}{ }^{0.184}}{I_{a n i}{ }^{0.821}} \\
& \text { For } I_{a n i} \geq 1, S_{\theta}=-2.48 \frac{\sin \theta^{5.87} h_{d}{ }^{0.152}}{I_{a n i}{ }^{0.964}}
\end{aligned}
$$

In related works, Yildiz and Ozkan (1998) [4], Ozkan, Yildiz, and Raghavan, (1999) [5], and Ozkan and Raghavan (2000) [6] investigated rate distribution and transient pressure behavior in perforated and slanted wells. Their applied calculation strategies for these types of wells were shown to boost both computational accuracy and efficiency. Sensitivity studies were also carried out by Suk Kyoon, Ouyang, and Huang (2008) [7] to determine analytical correlations that could be used to calculate deviated well productivity. The researchers found that the available semi-analytical correlations appeared to be unsuitable when applied to wells that had a deviation angle of $75^{\circ}$ or greater. Semi-analytical correlations also did not appear to be suitable in calculations for partially penetrating deviated wells. Additionally, they reviewed several different analytical solutions for the inflow performance relationship (IPR) and productivity index (PI). Their extensive review of the 
literature was augmented with case studies that compared correlations in similar categories as a means of building selection guidelines. Numerous empirical and theoretical models and correlations of variable reservoir parameters have been devised since Darcy's law was first proposed in 1856 [8]. These parameters include elements such as area, reservoir shape, time independence, well trajectory, and fluid phases.

In recent studies conducted by Wang, Xue, Gao, and Tong (2012) [9], a highly deviated well inflow model for an anisotropic reservoir was tested. Their results indicated that an increase in the anisotropy index effectively boosted the deviation angle effect on well productivity. In the same year, Ghahri and Jamiolahmady (2012) [10] conducted a sensitivity study that reviewed skin values from the work of Rogers and Economides (1996) [3]. They proposed that these values had been underestimated by the researchers and thus differed significantly in comparison to those produced by the models of Cinco et al. (1975) [1] and Besson (1990) [2] when applying the same or similar transformation models in isotropic media.

In a subsequent study, Feng and Liu (2014) [11] developed a mathematical model for testing inclined wells that featured impermeable faults using point source theory. Recently, Dong, Wang, and Wang (2018) [12] proposed a model for the skin factor of wells that were directionally drilled and partially penetrated in anisotropic reservoirs. Their aim was to simulate how slants were affected by flow and drilling. There are several drawbacks and limitations in the current models. For example, one limitation of the current models concerns perforation orientation with regard to top and bottom reservoir boundaries. In this situation, the perforations and bedding planes must be parallel. For perforated inclined wells, however, perforations typically deviate from the horizontal plane at angle $\theta$. In fact, some completion designs, such as the one presented in Figure 3 , show perforations of inclined wells being forced into an orientation parallel to the bedding plane.

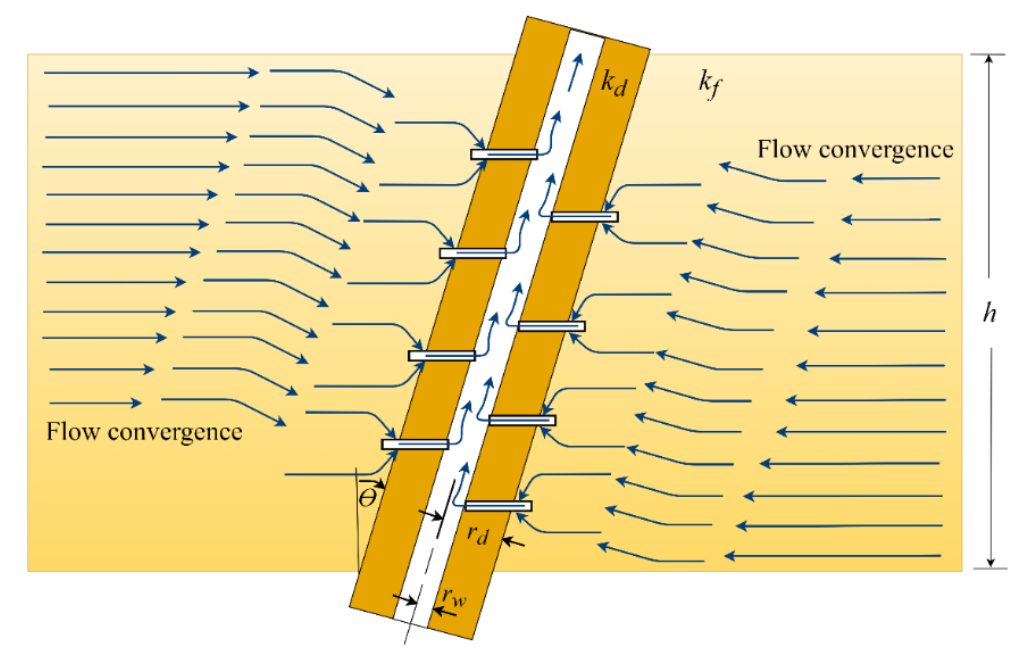

Figure 3. Schematic of inclined and completely perforated well with perforations parallel to radial flow direction and formation damage.

Earlier techniques to predict the pseudo-skin factor remain relatively impractical from an applicability perspective when considered for use in different reservoir types. This lack of practical applicability is caused by issues pertaining to computational accuracy and geometrical effects. More specifically, these aspects have persistently lacked sufficient accuracy and/or need to be processed through an elaborate transient numerical simulator. Accordingly, the primary aim of the present work is to present a numerical model that can simulate the real conditions of fluid flows in inclined wells. In order to compare and discuss the accuracy of the proposed model, the analytical model of Cinco et al. (1975) [1] and the Besson (1990) [2] anisotropic formulations were utilized as a basis for the comparison of numerical simulations of slant skin. This was accomplished by determining the differences between cases of vertical open-hole and inclined-well pressure drops. 


\section{Methodology}

This study is an extension of the work of Abobaker et al. (2021A) [13] and Abobaker et al. (2021B) [14], which conducts the two main investigative procedures of numerical and statistical analysis for more accurate estimation of the skin factor of inclined wells with anisotropic permeability. Abobaker et al. (2021A and 2021B) used the experimental schemes (2018 and 2019, $[15,16])$ as a radial flow cell (RFC). Their experiments carried out on fluid flows through the perforation samples primarily relied on rather simplistic assumptions, such as those presented by Rahman et al. (2006, 2007a, 2007b, 2008, and 2016) [17-21]. The results of numerical model used in this study were validated with the experimental data of studies' Abobaker et al. (2021A and 2021B). In this study, statistical analysis was coupled with numerical simulation to expand the investigation of fluid flow in the near-wellbore region by producing data that cannot be obtained experimentally due to limitations in the experimental setup and, especially, the small sample size.

\subsection{Numerical Simulation Procedure}

ANSYS (ANSYS Inc., Pittsburgh, PA, USA) fluent (3D) 18.1 was used for numerical simulations of fluid flow through a near-wellbore region. The cylindrical geometryincluding permeability anisotropy, wellbore radius, reservoir thickness, and deviation angle-were used to represent near-wellbore conditions in inclined wells. The single phase (water) was injected radially through the cylindrical near-wellbore region. In the case of an open-hole well, the inlet was specified as the outer formation zone surface, and the outlet was specified as the interior surface of the wellbore, as exhibited in Figure 4. The pressure at the outlet was set as equal to atmospheric pressure.

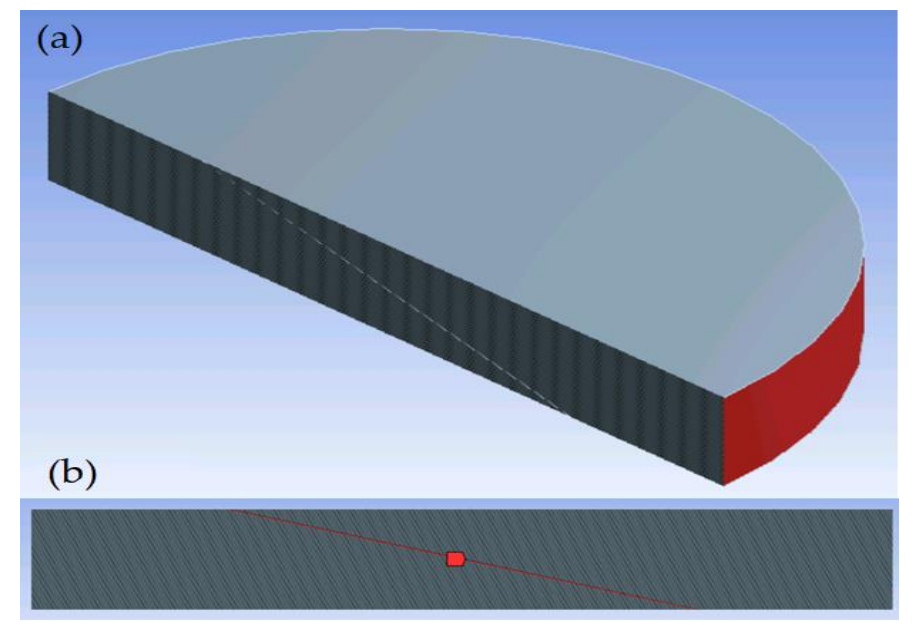

Figure 4. Vertical section for inlet (a) and outlet (b).

In the case of inclined wells with completely or partially perforated completions, two scenarios were suggested to verify the effect of perforation direction on the skin factor or pressure drop in inclined wells, as shown in Figure 5. In the first scenario, the direction of perforations was perpendicular to the wellbore with a perforation angle of $180^{\circ}$ in the direction of the well inclination. In the second, the direction of perforations was parallel to radial flow direction with the same perforation angle. The effect of increasing the three factors (perforation depth $L_{p}$, perforation diameter $r_{p}$, and penetration space $n_{p}$ ) on the skin factor was analyzed, as shown in Table 1. 


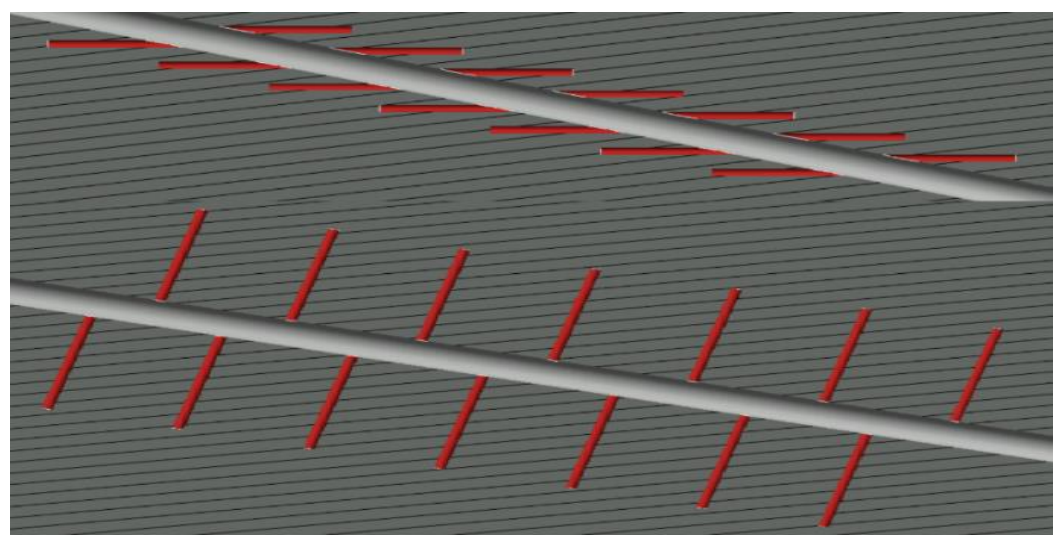

Figure 5. Schematic of inclined and completely perforated well with perforations parallel or perpendicular to well and formation damage.

Table 1. Dimensions and properties of the vertical near-wellbore region and the ranges of three investigated parameters.

\begin{tabular}{cc}
\hline Dimensions and Properties of the Sample & Values (Units) \\
\hline Reservoir or pay zone thickness $(h)$ & $2.66 \mathrm{~m}$ \\
Reservoir radius $\left(r_{e}\right)$ & $10 \mathrm{~m}$ \\
Formation permeability $\left(k_{f}\right)$ & $10^{-14} \mathrm{~m}^{2}$ \\
Porosity $(\varnothing)$ & $20 \%$ \\
Flow rate $(Q)$ & $2 \mathrm{~L} / \mathrm{min}$ \\
Viscosity of water $(\mu)$ & $0.00103 \mathrm{~kg} /(\mathrm{m} \cdot \mathrm{s})$ \\
Perforation depth $\left(L_{p}\right)$ & $30.48-91.44 \mathrm{~cm}$ \\
Perforation diameter $\left(r_{p}\right)$ & $1-2.5 \mathrm{~cm}$ \\
Penetration space $\left(n_{p}\right)$ & $1-5$ perforations $/ 30.48 \mathrm{~cm}$ \\
\hline
\end{tabular}

The uniform mesh and cut mesh methods were used to generate high quality mesh, as shown in Figure 6. This configuration contributed to the production of a high mesh density to capture the significant pressure gradients in the border regions.

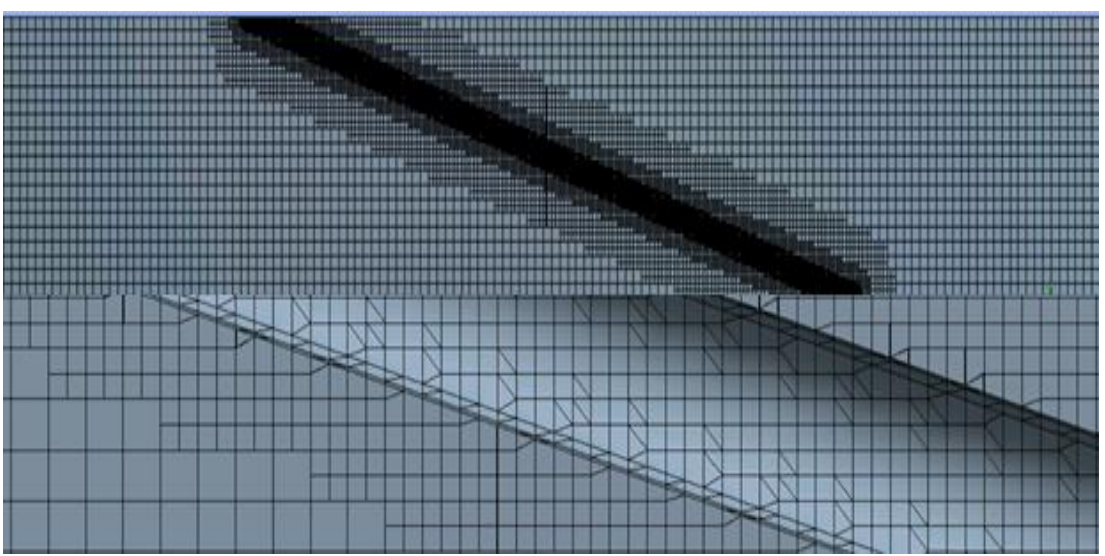

Figure 6. The shape of the uniform configuration mesh used in CFD simulations.

\subsection{Statistical Procedure}

Various strategies for investigating how several parameters or variables may affect experimental data were applied by utilizing the design of experiments (DoE) software. The first step in DoE is the determination of independent parameters and/or variables that may affect the experimental results. The second step includes determining the dependent variables [22]. The experiments generally run based on different parameter values, such 
that each run presents a combination associated with the specific variable value(s) being investigated. In this study, we used DoE with Box-Behnken design (BBD) to design the runs required for statistical analysis. The BBD, described as a design of response surface methodology, needs only three levels of parameters and/or variables in its experimental runs [23]. Then, the analysis of variance (ANOVA) was used to validate the proposed model statistically $[24,25]$. The three dimensionless parameters investigated included the ratio of reservoir thickness to wellbore radius, the permeability ratio, and the ratio of the well inclination angle to the maximum inclination angle $\left(\theta_{m}=75^{\circ}\right)$.

$$
\begin{aligned}
h_{d} & =\frac{h}{r_{w}} \\
k_{r} & =\frac{k_{h}}{k_{v}} \\
\theta_{d} & =\frac{\theta}{\theta_{m}}
\end{aligned}
$$

The ranges of the three dimensionless parameters for the inclined near-wellbore region are presented in Table 2.

Table 2. The ranges of the three dimensionless parameters.

\begin{tabular}{cc}
\hline Dimensions and Properties of the Sample & Values (Units) \\
\hline Ratio of reservoir thickness to wellbore radius $\left(h_{d}\right)$ & $80-540$ \\
Range of permeability ratio $\left(k_{r}\right)$ & $1-10$ \\
Range angle of the slant $(\theta)$ & $10^{\circ}-75^{\circ}$ \\
\hline
\end{tabular}

The flow rate for vertical wells in cylindrical near-wellbore regions with anisotropy permeability and Darcy flow perpendicular to the wellbore is expressed as:

$$
Q=\frac{2 \pi k_{f} h\left(p_{e}-p_{w f}\right)}{\mu\left[\ln \left(\frac{r_{e}}{r_{w}}\right)+S_{\theta}\right]}
$$

The skin factor can be obtained after the pressure drop is calculated from the simulation using:

$$
s_{\theta}=\frac{2 \pi k_{f} h\left(p_{e}-p_{w f}\right)}{Q \mu}-\ln \left(\frac{r_{e}}{r_{w}}\right)
$$

\section{Results and Discussion}

For the present work, a three-dimensional simulation model was built to investigate Darcy flow conditions for single-phase flow in a deviated well. The simulation results generated an extensive pressure gradient data bank covering the near-wellbore region, including variations for relevant parameters. The skin effect was quantified here by taking into account vertical-to-horizontal permeability anisotropy in the deviated wells. The results of numerical investigations showed that CFD simulation was able to predict the effect of an inclined well on the pressure gradient in the near-wellbore region, as shown in Figure 7. Based on these outcomes, our numerical model presents a streamlined method that significantly outperforms the requirements of 3D simulation as used in previously developed simulations. In fact, the simulation results agree with the actual flow performance by utilizing the skin effect applied to inclined wells. 


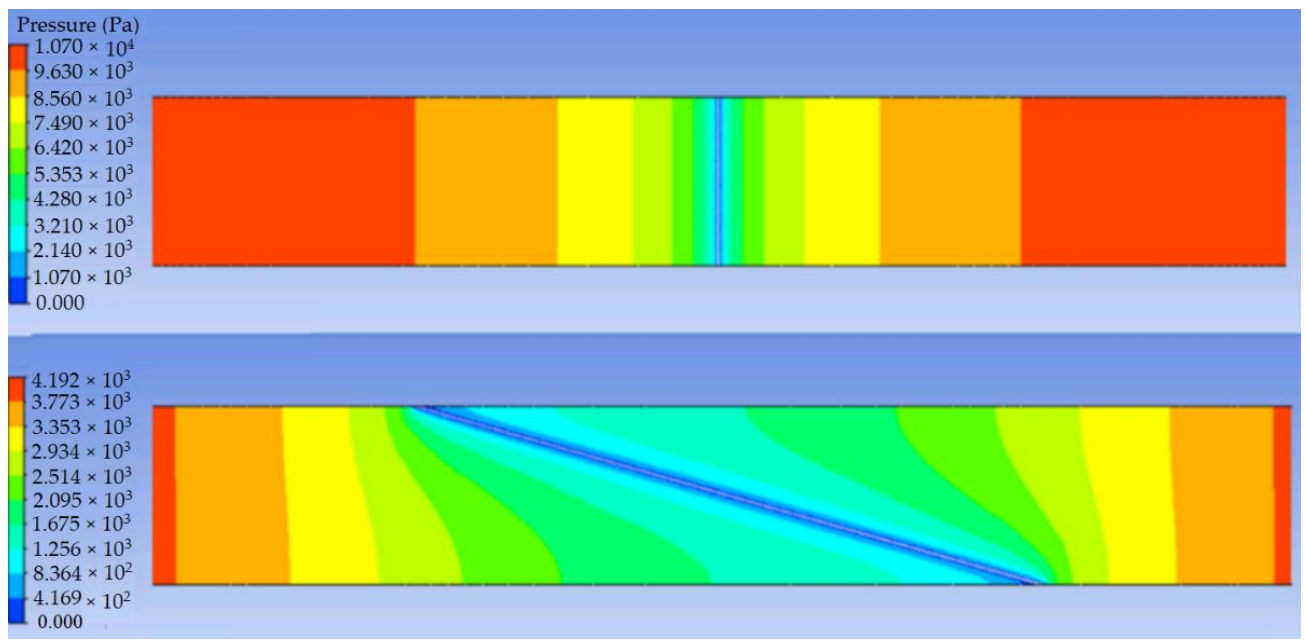

Figure 7. Numerical results of the pressure gradient through the near-wellbore region for vertical angle $90^{\circ}$ and inclination angle $75^{\circ}$ with two dimensionless parameters $\left(h_{d}=108.267, k_{r}=1\right)$ and flow rate $(Q=2 \mathrm{~L} / \mathrm{min})$.

Geometric skin essentially determines how geometry affects flow in a deviated wellbore. In Equation (14), the skin is utilized to determine the equivalent open-hole productivity and shows a flow rate that is nearly the same as that of the deviated wells. To construct the formula, a data bank was generated that includes geometrical parameter variations such as reservoir thickness, wellbore radius, deviation angle, formation properties, and anisotropy. A deviated well's flow regime can be divided into two regions to provide a deeper perspective. In such a division, one region represents the flow regime near the deviated well and is primarily affected by geometrical parameters. The other region is only slightly affected by geometrical parameters as the flow regime proceeds in a mostly radial pattern.

Twelve numerical runs were performed to obtain a statistical model deemed suitable via ANOVA analysis with the BBD model; the results of skin factor values for twelve numerical runs are shown in Table 3.

Table 3. Twelve numerical runs and the results of skin factor.

\begin{tabular}{ccccc}
\hline Runs & $\boldsymbol{h}_{\boldsymbol{d}}$ & $\boldsymbol{\theta}_{\boldsymbol{d}}$ & $\boldsymbol{k}_{\boldsymbol{r}}$ & $\boldsymbol{S}_{\boldsymbol{\theta}}$ \\
\hline 1 & 180 & 0.566665 & 10 & -0.35 \\
2 & 180 & 0.13333 & 5.5 & -0.0010 \\
3 & 180 & 1 & 5.5 & -2.9 \\
4 & 360 & 0.13333 & 10 & -0.02 \\
5 & 180 & 0.566665 & 1 & -1.32 \\
6 & 360 & 0.13333 & 1 & -0.1 \\
7 & 360 & 1 & 1 & -4.2 \\
8 & 360 & 1 & 10 & -2.22 \\
9 & 540 & 1 & 5.5 & -3.1 \\
10 & 540 & 0.566665 & 10 & -0.41 \\
11 & 540 & 0.13333 & 5.5 & -0.06 \\
12 & 540 & 0.566665 & 1 & -1.8 \\
\hline
\end{tabular}

The main assumption of the DoE model was the normal distribution of numerical data with a constant variance of features. Inspection of the normal plot of residuals in Figure 8 emphasizes the significant correlation between a normal distribution and the obtained data. Additionally, our results demonstrate that the predicted values derived from the statistical model share strong similarities with the actual values derived numerically. 


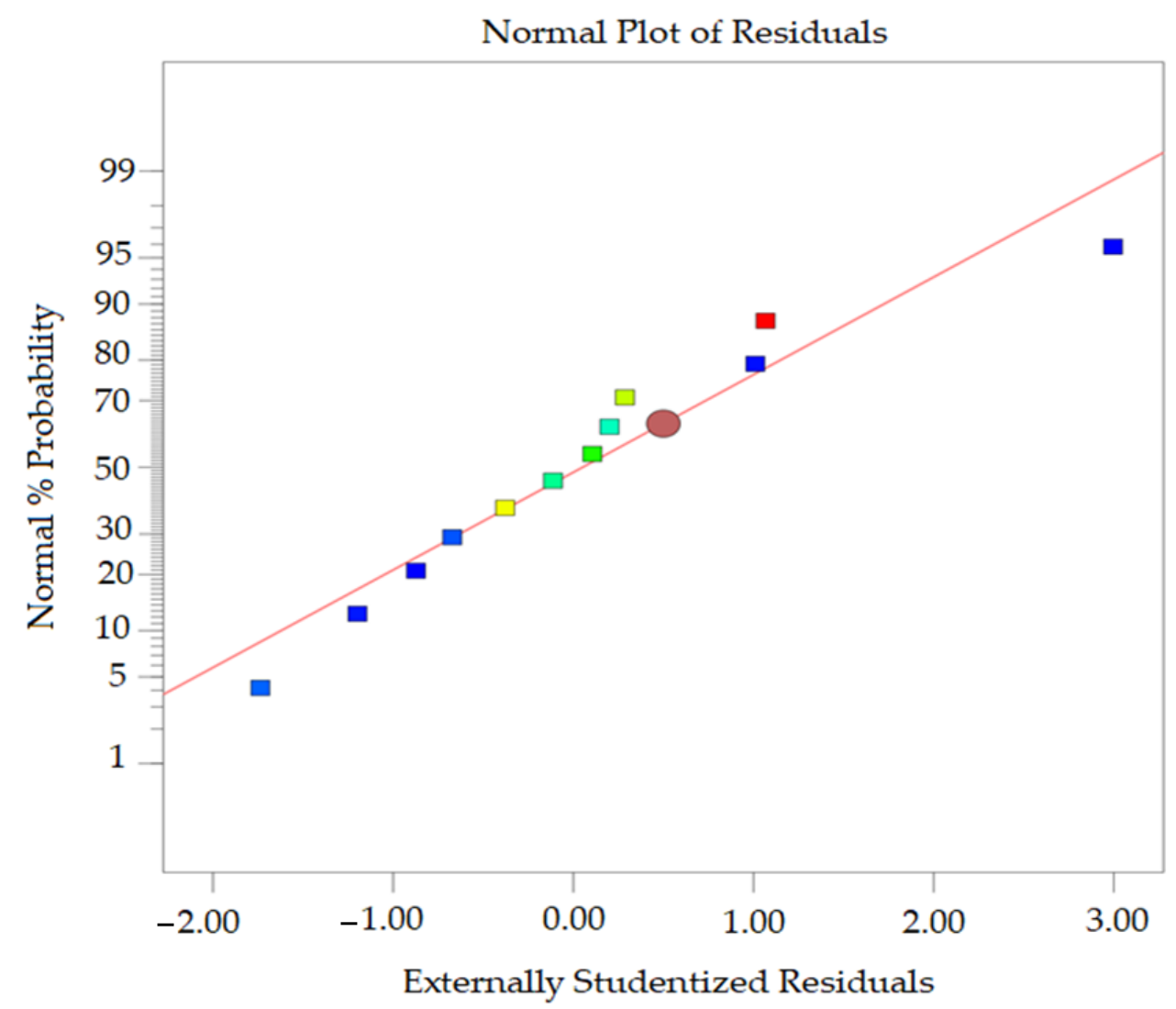

Figure 8. Normal plot of residuals.

The results reveal the interaction effect among the three dimensionless parameters $\left(h_{d}, \theta_{d}\right.$, and $\left.k_{r}\right)$. The two dimensionless parameters (the ratio of the angle of the slant to the maximum inclination angle and the permeability ratio) demonstrated a significant effect on the skin factor. The angle of the slant has significant effect on the reduction in pressure drop in the near-wellbore region due to the increase in the contact area between the well and the reservoir resulting from the increase in the angle of inclination, as exhibited in Figure 9. Additionally, anisotropy is a crucial parameter affecting deviated well productivity; the ratio of horizontal permeability to vertical permeability has a great effect on the skin factor with regard to the well productivity, by increasing the resistance of flow convergence and decreasing the performance of deviated wells, as exhibited in Figure 10. The study findings indicate that any reduction in vertical-to-horizontal permeability subsequently reduces deviated well performance. As a vector, permeability depends heavily on its measured direction and typically shows high levels of anisotropy. The index of anisotropy is critically important, and the calculated skin effects appear to differ significantly from calculations in the literature that were based on the assumption of complete isotropy. Hence, most common assumptions pertaining to permeability isotropy are unfounded.

The strategy applied in this study can be used to estimate the productivity of deviated wells and to optimize the angle and length of wells. Such optimization can be performed with a simple correlation alone, making it practical for application to a variety of purposes. Therefore, this study provides a correlation from the statistical analysis based on numerical results. This correlation utilized to determine the effect of the ratio of reservoir thickness to wellbore radius, and inclination angle on the pseudo-skin factor value, taking the anisotropy into account, is as follows:

$$
S_{\theta}=-\left(0.1+0.00025 \times h_{d}+1.852 \times \theta_{d}-0.056 \times k_{r}\right)^{2}
$$




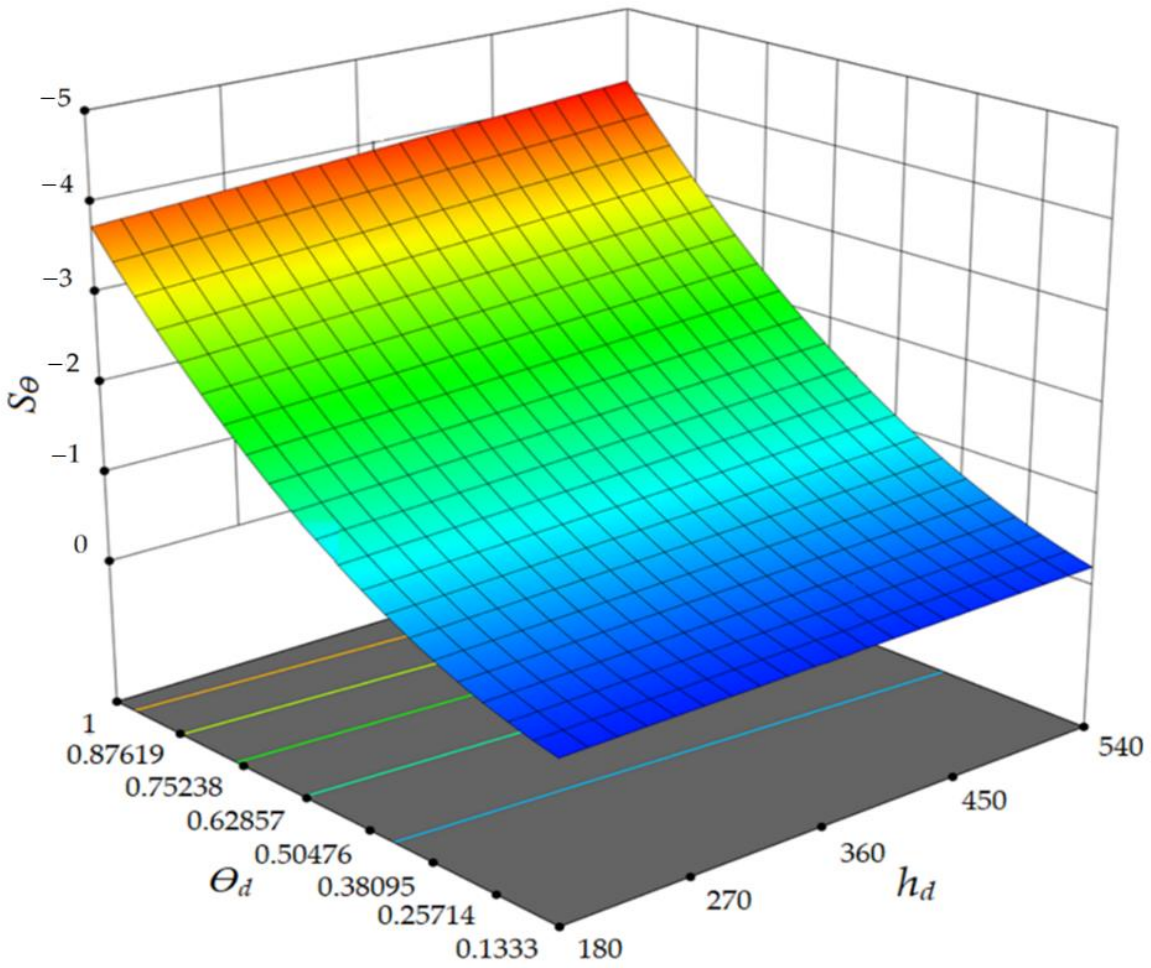

Figure 9. Effect of interaction between the two dimensionless parameters $\theta_{d}$ and $h_{d}$ on skin factor with constant value for the third dimensionless parameter $\left(k_{r}=1\right)$.

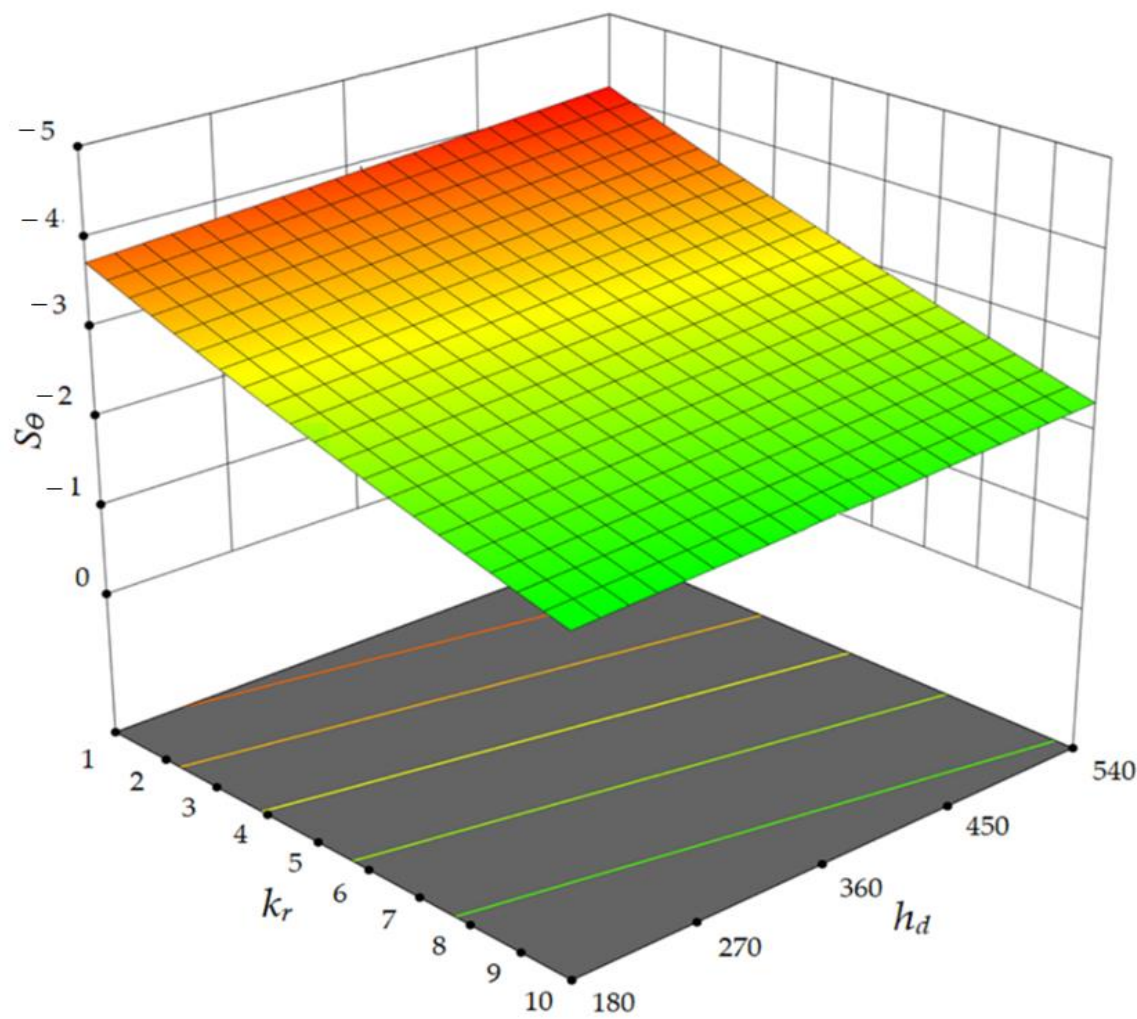

Figure 10. Effect of interaction between the dimensionless parameters $h_{d}$ and $k_{r}$ on skin factor with constant value for the third dimensionless parameter $\left(\theta_{d}=1\right)$.

The proposed correlation can be applied in deviation angles between $10^{\circ}$ and $75^{\circ}$. The resulting formula is highly efficient compared with those presented in the recent literature. A comparison between the current correlation and the slant skin models of 
Cinco et al. (1975) [1] and Besson (1990) [2] provides results for skin factors of highly deviated wells that produce at a constant flow rate. In the comparison, the effects of increasing the deviation angle and permeability ratio were investigated by assuming the impermeable top and bottom boundaries of the reservoir and the ratio of reservoir thickness to wellbore radius $\left(h_{d}=180\right)$. The comparison results indicate that, under conditions of weak anisotropy, the impact of the deviation angle on inflow performance is moderate. However, as anisotropy increases, the impact of the deviation angle increases. The comparison results demonstrate good agreement between the current correlation and the slant skin model results of Cinco et al. (1975) [1] and Besson (1990) [2], as shown in Figures 11 and 12. Additionally, the accuracy of the results of the proposed correlation was verified in numerous cases under constant flow conditions via comparison with available models. Overall, this approach presents a highly efficient method for the quantification of the skin factor of deviated wells.

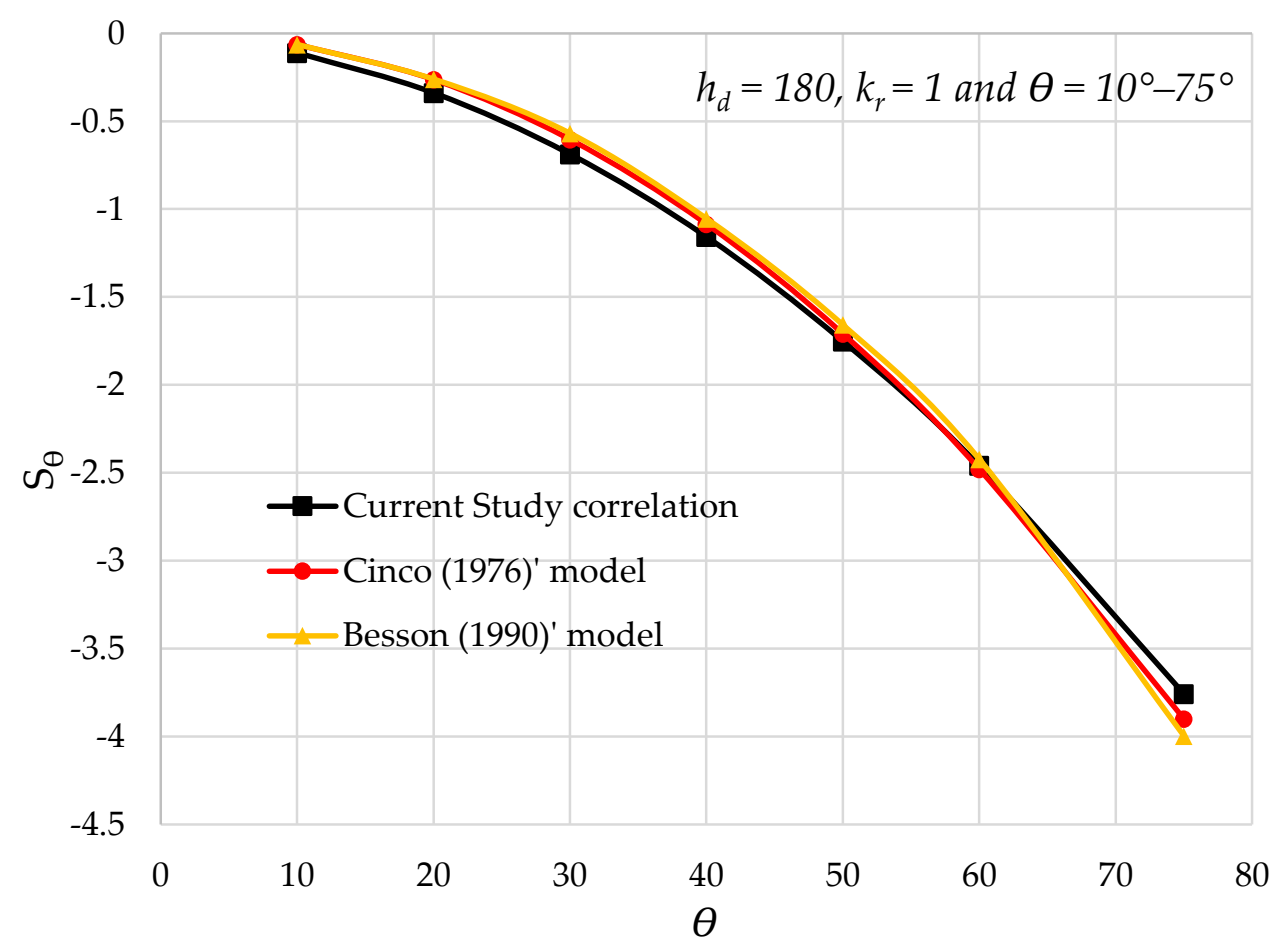

Figure 11. Comparison between the current correlation and the slant skin model results of Cinco et al. (1975) [1] and Besson (1990) [2] for increasing the angle of the slant $\left(10^{\circ}-75^{\circ}\right)$.

In inclined perforated well cases, when the direction of perforations is perpendicular to the wellbore or parallel to the radial flow direction, the results of numerical investigations reveal different pressure gradients for these two scenarios in the near-wellbore region, as shown in Figure 13. The results demonstrate the difference in skin factor $\left(S_{d}\right)$ or pressure gradient that result from the different directions of perforations in relation to the wellbore.

This contrast increases with an increase in the depth and diameter of the perforations and penetration space to reach a maximum value at critical values of the three parameters $\left(L_{p}=60.96 \mathrm{~cm}, r_{p}=2 \mathrm{~cm}\right.$, and $n_{p}=4$ perforations $\left./ 30.48 \mathrm{~cm}\right)$, after which it begins to decrease, as shown in Figures 14-16. Simultaneously, the increase in flow rate during the Darcy flow range does not show any effect on the variance in skin factor. The variance between the two scenarios results from an increase in the cross-area in the radial flow direction combined with a decrease in the flow convergence effect in the first scenario. Meanwhile, the perforation tips are subject to radial flow with increasing flow convergence in the second. This difference in the computation of pressure drop and the calculation of the skin factor depends on a complex interaction between several factors, including the depth and diameter of perforation, penetration space, perforation angle, and the inclination 
of the well. In this study, the variance between the two scenarios, including the effects of the indicated parameters, was investigated in the case of perforation direction at the same inclination as the well angle with a perforation angle of $180^{\circ}$. The interaction effect of other perforation angles with different configurations on the skin factor warrants further investigation.

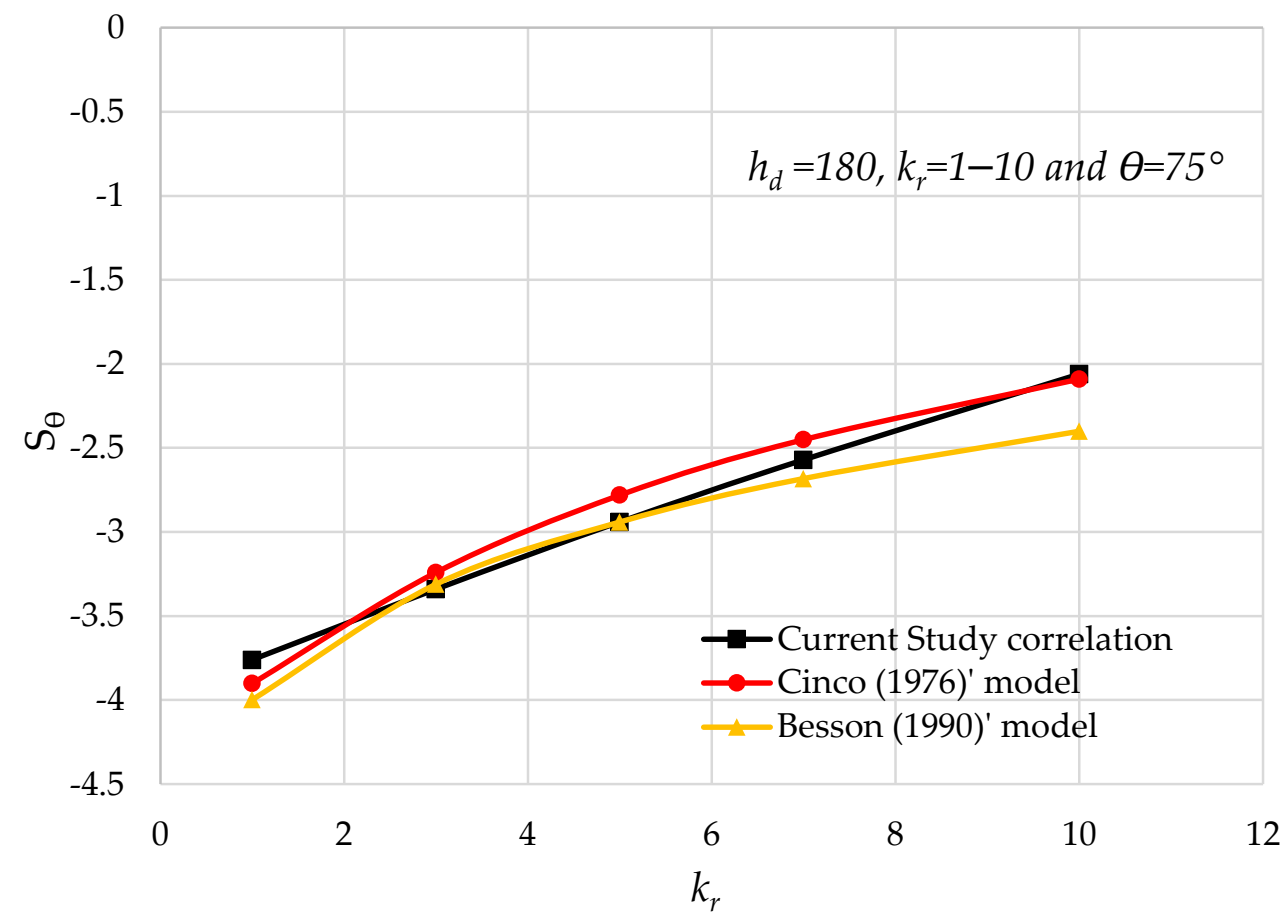

Figure 12. Comparison between the current correlation and the slant skin model results of Cinco et al. (1975) [1] and Besson (1990) [2] for increasing permeability ratio (1-10).

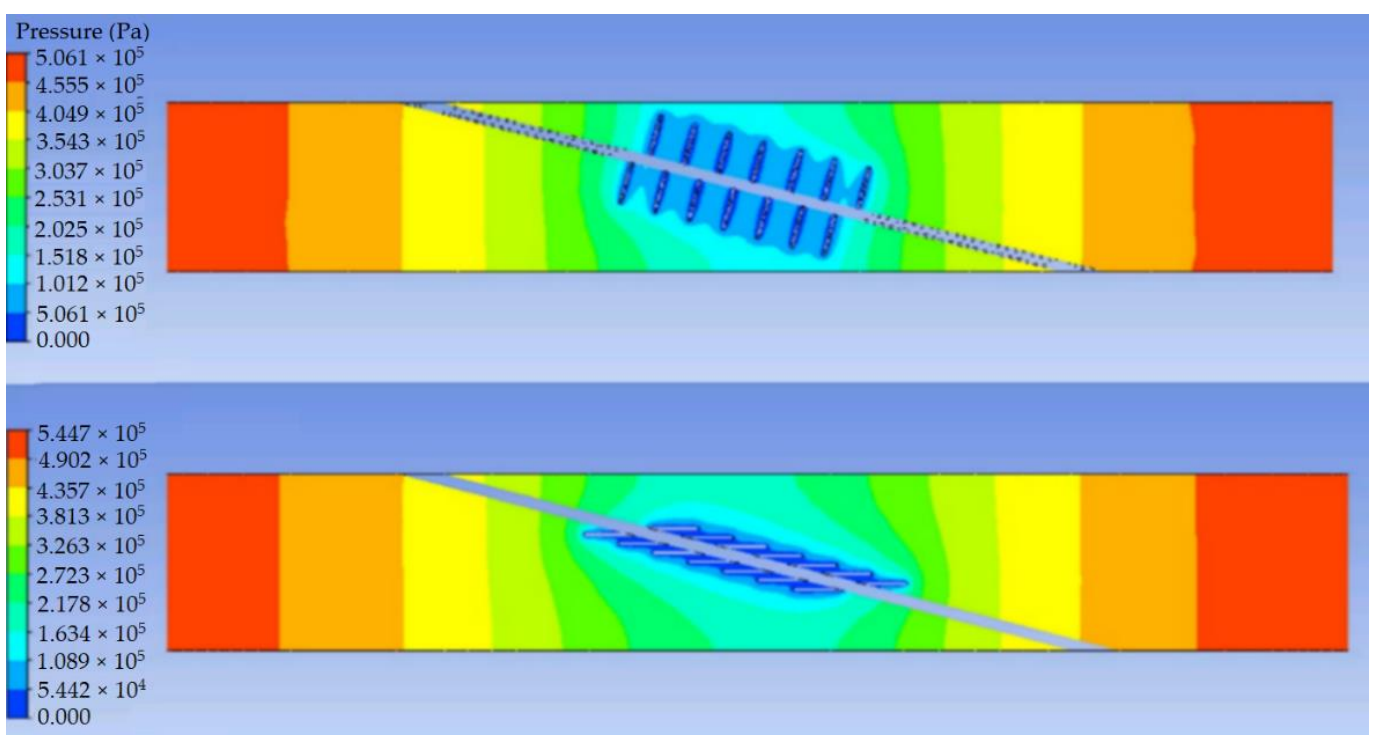

Figure 13. Numerical results for the pressure gradient through the near-wellbore region for two scenarios with maximum inclination angle $75^{\circ}, Q=2 \mathrm{~L} / \mathrm{min}, L_{p}=60.96 \mathrm{~cm}$, and $n_{p}=1$ perforation $/ 30.48 \mathrm{~cm}$ ). 


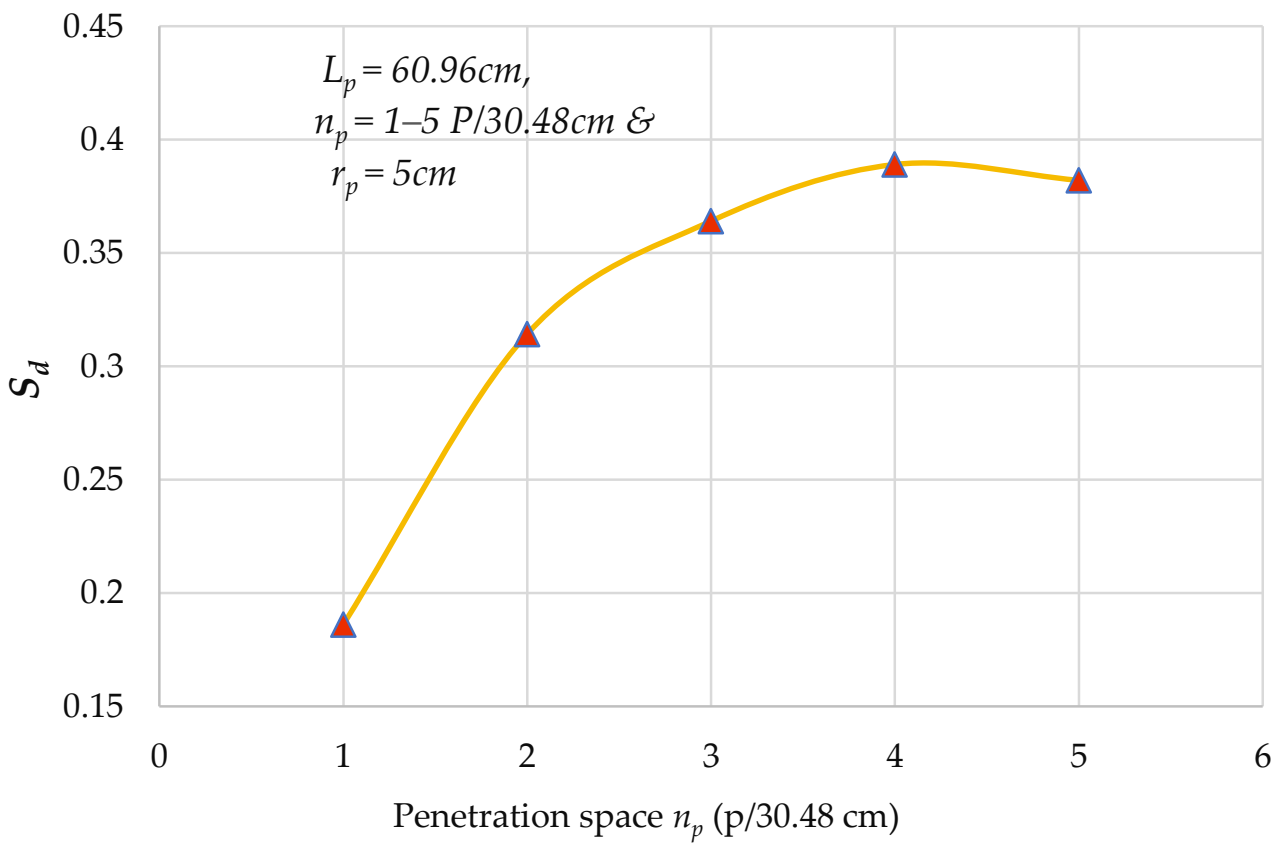

Figure 14. Difference in skin factor values for two perforation orientations with increasing penetration space $n_{p}(1-5$ perforations $/ 30.48 \mathrm{~cm})$.

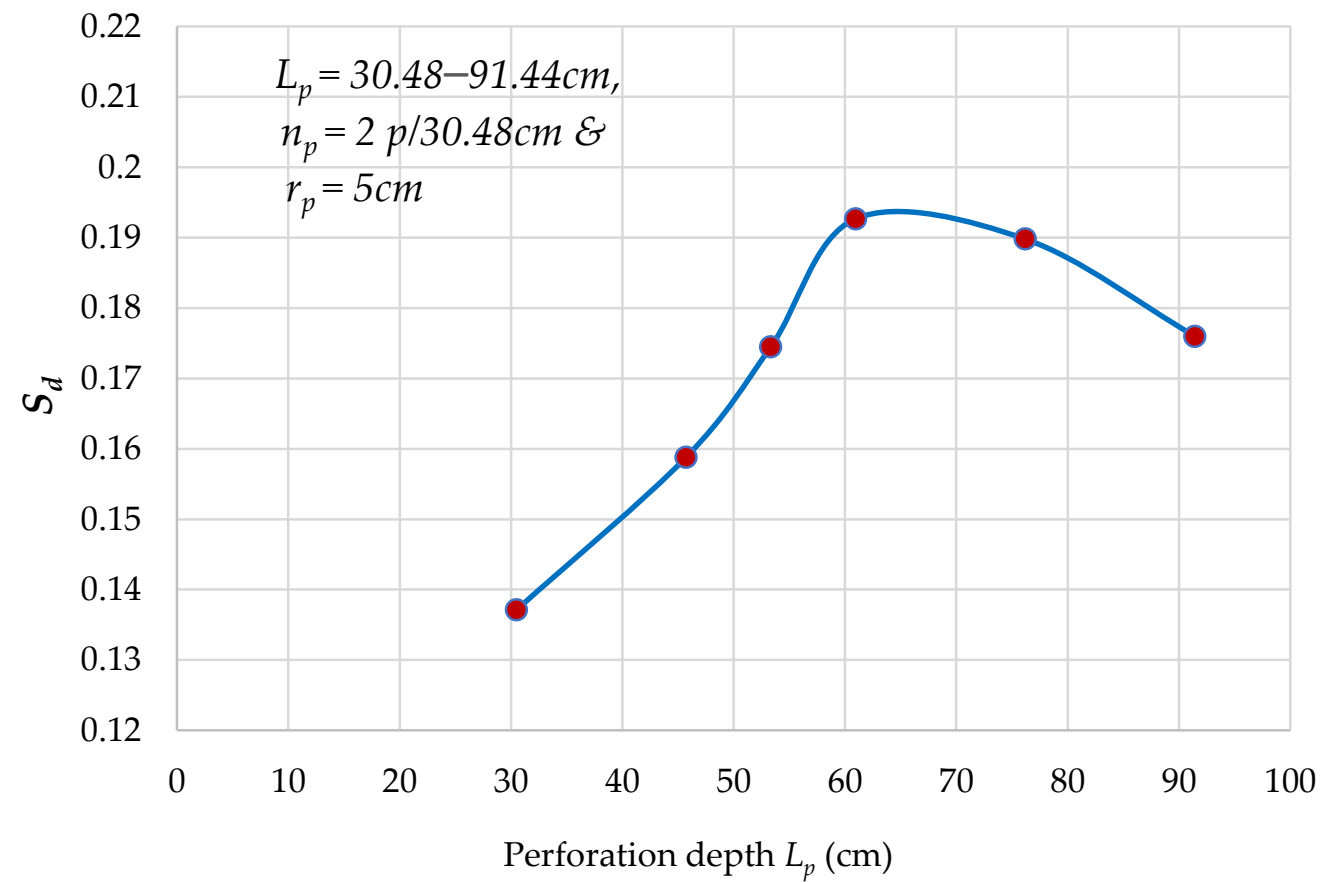

Figure 15. Difference in skin factor values for two perforation orientations with increasing perforation depth $L_{p}(30.48-91.44 \mathrm{~cm})$. 


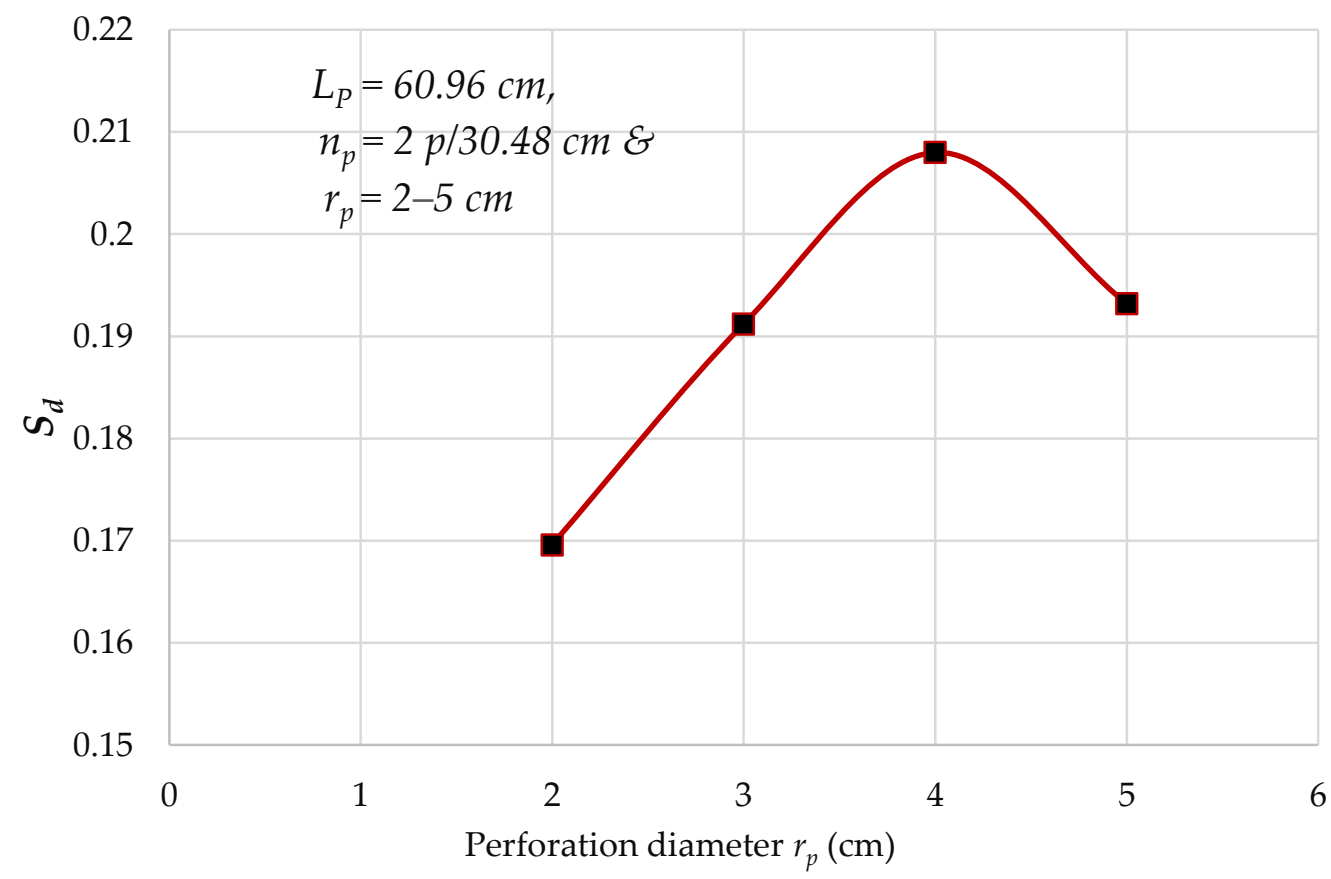

Figure 16. Difference in skin factor values of two perforation orientations with increasing perforation diameter $r_{p}(2-5 \mathrm{~cm})$.

\section{Conclusions}

This work was conducted in order to expand the knowledge regarding the effect of inclined wells on the skin factor and pressure gradient in a near-wellbore region. Based on numerical investigations, the following conclusions can be drawn:

1. Numerical investigations clearly indicated the effect of three dimensionless parameters $\left(h_{d}, \theta_{d}\right.$ and $\left.k_{r}\right)$ on the skin factor due to inclination in the vertical wells. The results demonstrate that the ratio of inclination angle to the maximum inclination angle $\left(75^{\circ}\right)$ and the permeability ratio significantly affect the skin factor and pressure drop in the near-wellbore region. In contrast, the ratio of reservoir thickness to wellbore radius $\left(h^{d}\right)$ has a more negligible effect.

2. In the case of an inclined open-hole well, the novel correlation presented in the current study simplifies the estimation of the skin factor of inclined wells at different inclination angles. Compared with other approaches, the novel correlation performs well by providing estimates of the skin factor that are relatively close to those of previous models.

3. In the case of an inclined perforated well, the results demonstrate the variance in skin factor and pressure gradient that result from the direction of perforations in relation to the wellbore:

a. This difference in the computation of pressure drop and the calculation of the skin factor depends on the complex interaction between several factors, including depth and diameter of perforation, penetration space, perforation angle, and the inclination of the well.

b. The difference between the results for the two scenarios indicates that currently available models for evaluating the skin factor of inclined perforated wells need to be improved in light of this variance.

Author Contributions: Conceptualization, E.A.; methodology, E.A.; simulation validation, E.A. and A.E.; writing-original draft preparation, E.A.; writing-review and editing, A.E. and K.N.; supervision, F.K., M.A.R. and A.A. All authors have read and agreed to the published version of the manuscript. 
Funding: This publication was made possible by grant NPRP10-0101-170091 from the Qatar National Research Fund (a member of the Qatar Foundation). Statements made herein are solely the responsibility of the authors.

Institutional Review Board Statement: Not applicable.

Informed Consent Statement: Not applicable.

Data Availability Statement: All data are contained within the article.

Conflicts of Interest: The authors declare no conflict of interest.

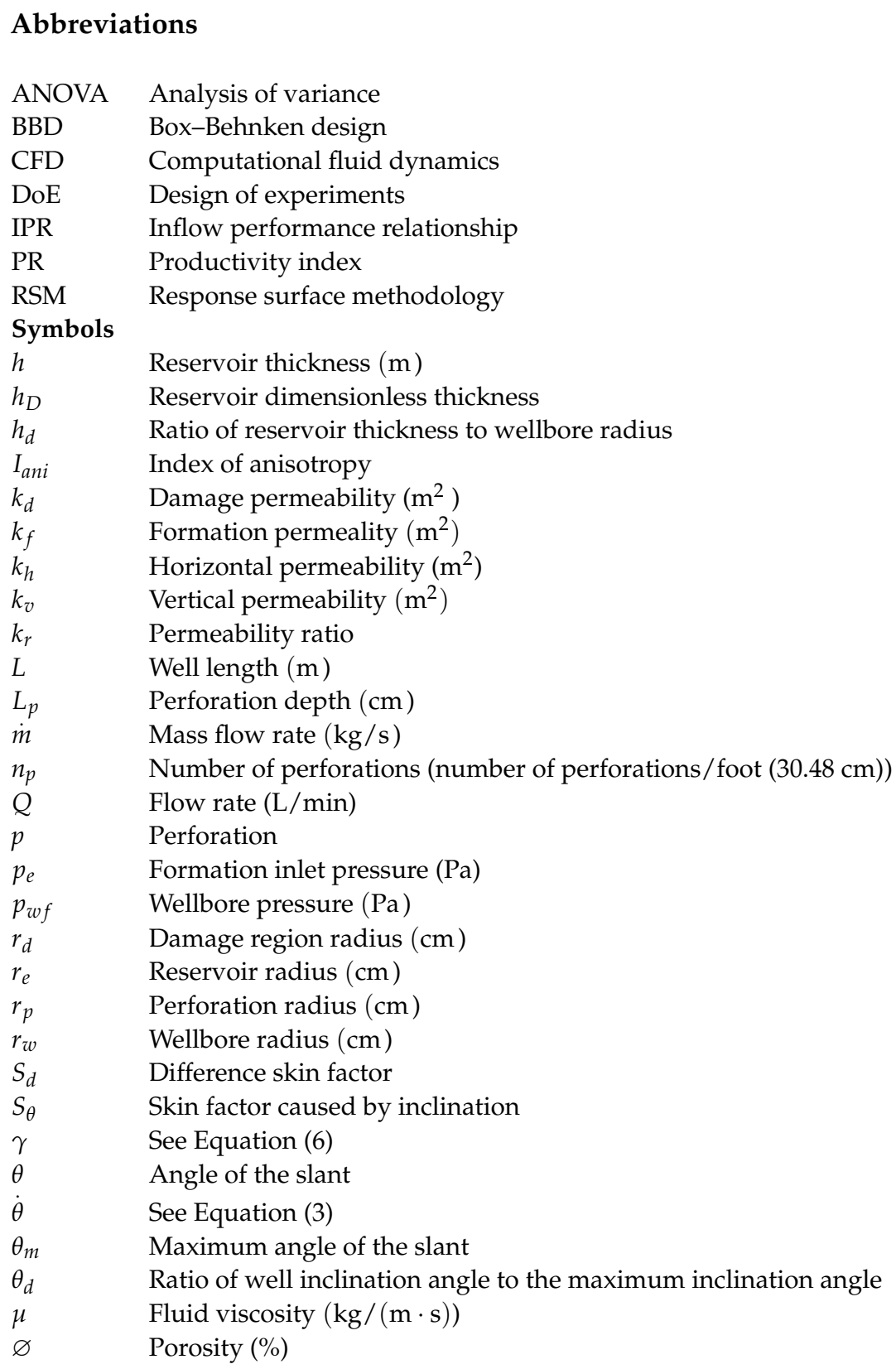

\section{References}

1. Cinco, H.; Miller, F.G.; Ramey, H.J., Jr. Unsteady-state pressure distribution created by a directionally drilled well. J. Pet. Technol. 1975, 27, 1392-1400.

2. Besson, J. Performance of slanted and horizontal wells on an anisotropic medium. In Proceedings of the European Petroleum Conference, Hague, The Netherlands, 21-24 October 1990.

3. Rogers, E.J.; Economides, M.J. The skin due to slant of deviated wells in Permeability-Anisotropic reservoirs. In Proceedings of the International Conference on Horizontal Well Technology, Calgary, Alta., Canada, 18-20 November 1996. 
4. Yildiz, T.; Ozkan, E. Pressure-transient analysis for perforated wells. In Proceedings of the SPE Annual Technical Conference and Exhibition, New Orleans, LA, USA, 27-30 September 1998.

5. Ozkan, E.; Yildiz, T.; Raghavan, R. Pressure-Transient analysis of Perforated slant and horizontal wells. In Proceedings of the SPE Annual Technical Conference and Exhibition, Houston, TX, USA, 3-6 October 1999.

6. Ozkan, E.; Raghavan, R. A computationally efficient, transient-pressure solution for inclined wells. SPE Reserv. Eval. Eng. 2000, 3, 414-425.

7. Kyoon, C.S.; Ouyang, L.-B.; Huang, W.S.B. A comprehensive comparative study on analytical pi/ipr correlations. In Proceedings of the SPE Annual Technical Conference and Exhibition, Denver, CO, USA, 21-24 September 2008.

8. Darcy, H. Les Fontaines Publiques de la Ville de Dijon; Dalmont: Paris, France, 1856.

9. Wang, H.; Xue, S.; Gao, C.; Tong, X. Inflow performance for highly deviated wells in anisotropic reservoirs. Pet. Explor. Dev. 2012, 39, 239-244.

10. Ghahri, P.; Jamiolahmady, M. A new, accurate and simple model for calculation of productivity of deviated and highly deviated well-part I: Single-phase incompressible and compressible fluid. Fuel 2012, 97, 24-37.

11. Feng, G.-q.; Liu, Q.-g. Pressure transient behavior of a slanted well with an impermeable fault. J. Hydrodyn. 2014, 26, 980-985.

12. Dong, W.; Wang, X.; Wang, J. A new skin factor model for partially penetrated directionally-drilled wells in anisotropic reservoirs. J. Pet. Sci. Eng. 2018, 161, 334-348.

13. Abobaker, E.; Elsanoose, A.; Khan, F.; Rahman, M.A.; Aborig, A.; Noah, K. Quantifying the partial penetration skin factor for evaluating the completion efficiency of vertical oil wells. J. Pet. Explor. Prod. Technol. 2021, 11, 3031-3043.

14. Abobaker, E.; Elsanoose, A.; Khan, F.; Rahman, M.A.; Aborig, A.; Butt, S. Comparison of Crushed-zone skin factor for cased and PERFORATED WELLS calculated with and without including a Tip-Crushed Zone effect. Geofluids 2021, $2021,1-13$.

15. Ahammad, M.; Rahman, M.; Zheng, L.; Alam, J.M.; Butt, S.D. Numerical investigation of Two-phase fluid flow in a perforation tunnel. J. Nat. Gas Sci. Eng. 2018, 55, 606-611.

16. Ahammad, M.J.; Rahman, M.A.; Butt, S.D.; Alam, J.M. An experimental development to characterise the Flow phenomena at THE Near-Wellbore Region. In Proceedings of the ASME 2019 38th International Conference on Ocean, Offshore and Arctic Engineering, Glasgow, Scotland, UK, 9-14 June 2019.

17. Rahman, M.A.; Heidrick, T.; Fleck, B.; Koksal, M. Enhancement of the completion efficiency of perforation tunnels in petroleum wells. In Proceedings of the ASME 2006 2nd Joint U.S.-European Fluids Engineering Summer Meeting Collocated With the 14th International Conference on Nuclear Engineering, Miami, FL, USA, 17-20 July 2006.

18. Rahman, M.A. Scale-up of perforation process from laboratory model to bottom hole dimensions. J. Porous Media 2008, 11, 19-34.

19. Rahman, M.A.; Mustafiz, S.; Biazar, J.; Koksal, M.; Islam, M.R. Investigation of a novel perforation technique in petroleum wells-Perforation by drilling. J. Frankl. Inst. 2007, 344, 777-789.

20. Rahman, M.A.; Mustafiz, S.; Koksal, M.; Islam, M.R. Quantifying the skin factor for estimating the completion efficiency of perforation tunnels in petroleum wells. J. Pet. Sci. Eng. 2007, 58, 99-110.

21. Zheng, L.; Rahman, M.A.; Ahammad, M.J.; Butt, S.D.; Alam, J.M. Experimental and numerical investigation of a novel technique for perforation in petroleum reservoir. In Proceedings of the SPE International Conference and Exhibition on Formation Damage Control, Lafayette, LA, USA, 24-26 February 2016.

22. Davim, J.P. Design of Experiments in Production Engineering; Springer: Cham, Switzerland, 2016.

23. Box, G.E.P.; Cox, D.R. An analysis of transformations. J. R. Stat. Soc. Ser. B (Methodol.) 1964, 26, 211-243.

24. Box, G.E.P.; Behnken, D.W. Some new three level designs for the study of quantitative variables. Technometrics 1960, 2, 455-475.

25. Ferreira, S.L.C.; Bruns, R.E.; Ferreira, S.H.; Matos, G.D.; David, J.M.; Brandão, G.C.; da Silva, E.G.P.; Portugal, L.A.; dos Reis, P.S.; Souza, A.S.; et al. Box-Behnken design: An alternative for the optimization of analytical methods. Anal. Chim. Acta. 2007, 597, 179-186. 